\title{
INVESTIGATION OF HEAT TRANSFER IN SEERSUCKER WOVEN FABRICS USING THERMOGRAPHIC METHOD
}

\author{
P. Zgórniak ${ }^{1}$, M. Matusiak*,2, L. Frącczak ${ }^{1}$ \\ 1 Faculty of Mechanical Engineering, Institute of Machine Tools and Production Engineering, Lodz University of Technology, Lodz, Poland \\ 2 Faculty of Material Technologies and Textile Design, Institute of Architecture of Textiles, Lodz University of Technology, Lodz, Poland \\ *Corresponding author. Email: malgorzata.matusiak@p.lodz.pl
}

\begin{abstract}
:
Seersucker woven fabrics are characterized by unconventional structure and surface topography. Their crucial feature is a three-dimensional puckered effect created by puckered and flat strips occurring in the warp direction. Such a structure influences the basic mechanical and utility properties of the fabrics. The aim of the presented work is to analyze the heat transfer in seersucker woven fabrics. Measurement of the heat transfer was done using an infrared camera. Thermograms created for different seersucker woven fabrics, as well as for flat and puckered areas of the seersucker woven fabrics, were analyzed from the aspect of heat exchange between a hot plate and the environment through the fabric. The results showed that the linear density of the weft yarn influences the heat transfer through seersucker woven fabrics. The results allowed the comparison of the heat transfer through the seersucker woven fabrics in both flat and puckered areas. The investigations performed confirmed that the thermographic method can be applied to complex analyses of the heat transfer through seersucker woven fabrics.
\end{abstract}

\section{Keywords:}

Heat transfer, infrared camera, seersucker woven fabrics, thermography

\section{Introduction}

Seersucker fabrics create a unique 3D woven structure. Such a 3D structure is characterized by alternating puckered and flat strips in the warp direction. Seersucker woven fabric can be received on loom by the application of two warps of different tensions [1]. There are also other methods for the manufacture of seersucker woven fabrics, for instance, thermal or chemical. Occurrence of the puckered strips along the warp causes the thickness of the fabric to be more than the thickness of typical flat woven fabrics of basic or derivative weaves. In the same way, thermal resistance of the seersucker woven fabrics is higher in comparison with the thermal resistance of standard woven fabrics. Some researchers [2, 3] consider that seersucker fabrics have good comfort properties, which result from their puckered structure. The puckered effect generates air spaces between the wearer's body and the fabric. It ensures the cooling of the user's body in hot conditions because the puckered area of the seersucker fabric holds the fabric away from the skin and facilitates air circulation.

Matusiak and Fracczak [4] showed that seersucker woven fabrics are characterized by low values of thermal absorptivity in the wet state. According to Bajzik et al. [5], this characteristic means that the seersucker woven fabrics are able to ensure good physiological comfort. Investigations have also shown that the thermal resistance of seersucker woven fabrics is significantly higher than the thermal resistance of standard woven fabrics made of the same fibers. This results from the much bigger thickness of the seersucker fabrics in comparison with the thickness of standard woven fabrics.

Thermal resistance of the textile materials is commonly measured by using a "skin model" and/or Alambeta device. The "skin model" provides the values of thermal resistance and water vapor resistance. Each parameter is determined using separate procedures. The Permetest device is considered a portable "skin model" because the Permetest measurement uses a procedure that is in agreement with the International Organization for Standardization (ISO) 11092 standard, which regulates the measurements using a "skin model" $[6,7]$.

The Alambeta device measures seven different parameters, characterizing - in a complex way - the textile materials from the point of view of their thermal insulation. They are the following: thermal conductivity, thermal absorptivity, thermal resistance, thermal diffusivity, maximal heat flow density, ratio of maximal to stationary heat flow density, and fabric thickness [8].

In the case of the "skin model" and the Permetest, air flow takes place in the measuring channel. The puckered surface of the seersucker woven fabrics can cause turbulences in air movement and, thus, can influence the results.

In the case of the Alambeta measurement, the fabric being measured is placed between the two plates of the device, which are maintained hot (upper) and cold (lower). While analyzing 
the seersucker woven fabrics, the value of thermal resistance, in fact, is a sum of the thermal resistance of the fabric and the thermal resistance of the air between the fabric and the surfaces of both plates (Figure 1).

Air trapped in small gaps is a good thermal insulator. Due to this fact, the results of thermal resistance determined by the Alambeta method are affected by the error resulting from the presence of air in the measured space.

Additionally, the thermal resistance of the seersucker woven fabrics should be different for the flat and puckered areas of the fabric. The above-mentioned methods of measurement do not allow assessing the thermal resistance of both fractions of the fabric separately.

Taking the above considerations into account in the current work, thermal measurements of the seersucker woven fabrics in the range of their thermal insulation has been performed using an infrared camera. The thermographic method has already been applied in measurements of textile materials. Michalak and Więcek [9] and Michalak et al. [10] measured the thermal conductivity of nonwovens. The method was based on simultaneous thermovision measurements of temperature on both sides of the material tested during heating or cooling. According to the authors' declaration, the developed method can be used for investigating the thermal characteristics of smart textiles. Matusiak and Sikorski [11] applied an infrared camera for evaluation of the heat transfer in clothing products to validate the thermal comfort index.

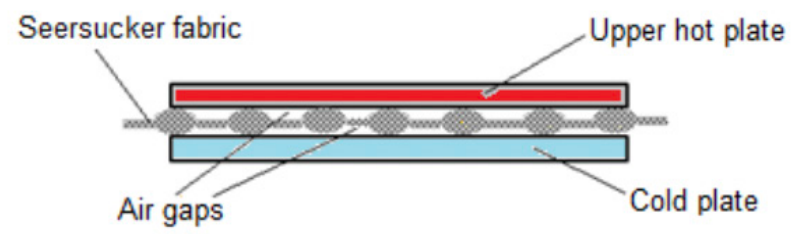

Figure 1. Principle of measurement of thermal resistance using the Alambeta device.

\section{Materials and methods}

In the current work, three kinds of seersucker woven fabrics were used as the objects of the investigation. They comprised seersucker woven fabrics with the same repeat of the seersucker effect and different weft yarns. The repeat of the seersucker effect was as follows:

- $\quad$ width of puckered strips $-5 \mathrm{~mm}$;

- $\quad$ width of flat strips $-8 \mathrm{~mm}$.

Both warps, the basic and the puckering patterns were made from the same plied yarn: 20 tex $\times 2$ cotton. As a weft, the following plied yarns were used: 20 tex $\times 2,25$ tex $\times 2$, and 30 tex $\times 2$. They were also yarns made of cotton.

The basic parameters of the investigated fabrics are presented in Table 1.

Measurement was performed using an FLIR SC6000HS infrared camera (Figure 2). The FLIR SC6000HS thermal imaging camera uses an indium antimonide $(\mathrm{InSb})$ detector to record thermal images, which allows the recording of thermal radiation in the spectral range from $3 \mathrm{~mm}$ to $5 \mathrm{~mm}$ with a resolution of $640 \times 512$ dots per inch (dpi), which corresponds to a pixel size of $25 \times 25 \mu \mathrm{m}$.

The measuring setup (Figure 2) also included a hot water tank (2), whose temperature was monitored continuously during the sequence of thermal pictures. In order to unify the temperature of the heat source, it was necessary to use matte black panels with the same emissivity factor $(\varepsilon=1)$ and dimensions. One of the plates (3) was placed on a container with hot water, while the other (5) was used to press the fabric (4) against the first hot plate (3). The plates used have the properties of good heat distribution within themselves; therefore, the temperature distribution on the plates was uniform for the whole plates, which can be seen in Figure 3 (Polygon 2). As a result of this approach, the unevenness of the water temperature in the tank

Table 1. Basic parameters of the seersucker woven fabrics being investigated

\begin{tabular}{|c|c|c|c|c|}
\hline Parameter & Unit & \multicolumn{3}{|c|}{ Value } \\
\hline Weave: Warp 1 & - & \multicolumn{3}{|c|}{ Plain } \\
\hline Weave: Warp 2 & - & \multicolumn{3}{|c|}{$\operatorname{Rep} 2 / 2$} \\
\hline Symbol & - & $1 / 1$ & $1 / 2$ & $1 / 3$ \\
\hline Weft yarn & - & 20 tex $\times 2$ & 25 tex $\times 2$ & 30 tex $\times 2$ \\
\hline Warp density & $\mathrm{cm}^{-1}$ & 12.7 & 11.9 & 12.8 \\
\hline Weft density & $\mathrm{cm}^{-1}$ & 11.4 & 11.1 & 10.4 \\
\hline Mass per square meter & $\mathrm{g} \mathrm{m}^{-2}$ & 212.9 & 233.0 & 253.0 \\
\hline Take-up: Warp 1 & $\%$ & 8.3 & 7.3 & 7.9 \\
\hline Take-up: Warp 2 & $\%$ & 49.8 & 56.0 & 60.2 \\
\hline Take-up: weft & $\%$ & 7.1 & 8.6 & 8.7 \\
\hline $\begin{array}{c}\text { Thickness (standard } \\
\text { deviation) }\end{array}$ & $\mathrm{mm}$ & $1.78(0.16)$ & $1.85(0.12)$ & $2.12(0.15)$ \\
\hline
\end{tabular}



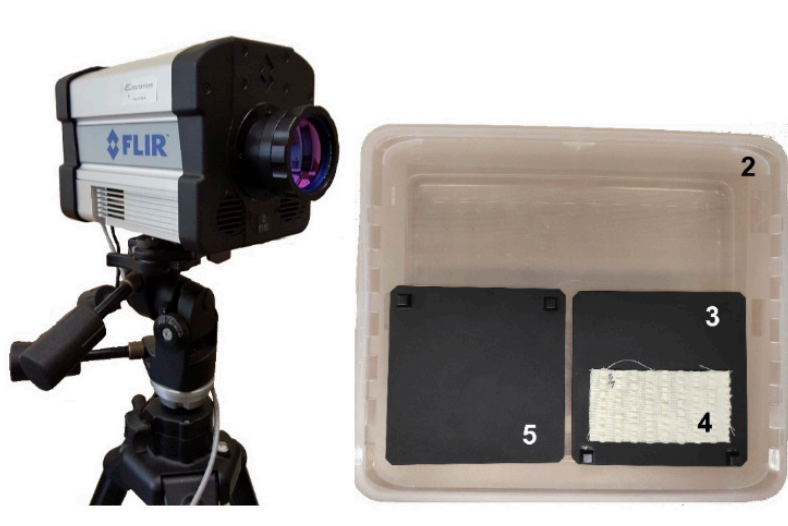

Figure 2. The measuring setup applied in the experiment and its components: (1) FLIR SC6000HS infrared camera, (2) water tank, (3) lower plate, (4) fabric sample, and (5) upper plate.

is compensated for by the measuring plate. Then, the thermal pictures' sequence was recorded, after removing the plate (5) from the fabric surface. The thermal pictures included the area of sample being measured and the corresponding area of the hot plate. Due to this, the thermal pictures allowed the monitoring of the temperature of the hot plate during the test. This process was repeated three times for each variant of fabric. The ambient temperature was about $20^{\circ} \mathrm{C}$, and the fabric surface was $1 \mathrm{~m}$ away from the lens of the infrared camera.

The acquisition and analysis of the measurement data were carried out using the FLIR Research IR Max program (Figure 3). The MATLAB package was used for statistical processing of the obtained results.

It was assumed that the temperature of the heat source would be similar to the temperature of the human body. For this purpose, as a source of heat, a water container was used, on the top of which a black aluminum plate with a known emissivity factor was placed. In addition, the heat capacity of the plate ensured a homogeneous temperature distribution. The tested fabric was then placed on the plate and covered with a second plate to ensure fabric contact with the hot plate. Thermal images were taken at a $30-\mathrm{Hz}$ frequency. The thermal image sequences obtained in this way were used to examine the changes in the distribution of temperature fields on the fabric surface over a set period of time.

\section{Results and discussion}

To test the steady state, measurements were carried out on the same type of fabric at $30,60,90$, and 120 seconds with a frequency of $30 \mathrm{~Hz}$. Because the temperature of the hot plate differed slightly in subsequent tests, two areas of data analysis were built to determine the temperature difference between the hot plate and the fabric. The first one with a lower temperature (Polygon 1) involved the temperature of the fabric (Figure 4), while the second area (Polygon 2) referred to the temperature of the heating plate (Figure 5).

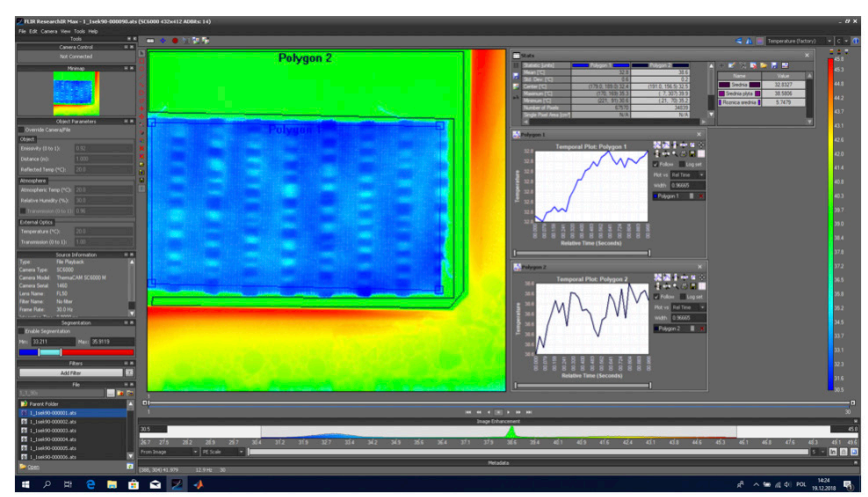

Figure 3. Interface of program for thermal image acquisition.

The development of the measurement method was complicated because the position of subsequent fabrics tested in relation to the hob slightly differed. For this purpose, the field and shape of the polygon determining the temperature of the hob had to be modified. The dimensions of the fabric sample were uniform, while the inevitable differences in position on the plate forced the need to modify the position also in the case of the polygon of the fabric analysis (Polygon 1). Using the statistical tools of the program, the average values from two polygons and the difference in average temperatures were recorded.

On the basis of the results from the FLIR SC6000HS infrared camera, the mean, maximum, and minimum values of the surface temperature were determined for both polygons. The results are presented in Table 2.

Higher temperature was detected for the hot plate surface than for the fabric sample. It is obvious, because the fabric creates a barrier for heat transfer from the hot plate surface to the outer surface of the fabric and to the environment. The difference between the mean temperatures of both the surfaces was $5.75^{\circ} \mathrm{C}$.

The results thus obtained were used to develop the charts presenting the temperature difference $(\Delta T)$ between the temperatures of the plate and the fabrics being measured against time (Figure 6).

For the $1 / 1$ fabric variant (Figure 6 - blue lines), measurements were performed at different plate temperatures. It was found that the initial temperature of the hot plate is important and that it influences the changes in the temperature difference between the surface of the plate and the fabric. A higher initial

Table 2. Results from the FLIR SC6000HS infrared camera for hot plate and fabric surface

\begin{tabular}{|c|c|c|c|}
\hline Parameter & Unit & $\begin{array}{c}\text { Polygon1 } \\
\text { (fabric) }\end{array}$ & $\begin{array}{c}\text { Polygon 2 } \\
\text { (hot plate) }\end{array}$ \\
\hline Mean temperature & ${ }^{\circ} \mathrm{C}$ & 32.83 & 38.58 \\
\hline Standard deviation & ${ }^{\circ} \mathrm{C}$ & 0.6 & 0.2 \\
\hline Maximum temperature & ${ }^{\circ} \mathrm{C}$ & 35.3 & 39.9 \\
\hline Minimum temperature & ${ }^{\circ} \mathrm{C}$ & 30.6 & 35.2 \\
\hline Number of pixels & - & 67,570 & 34,839 \\
\hline
\end{tabular}




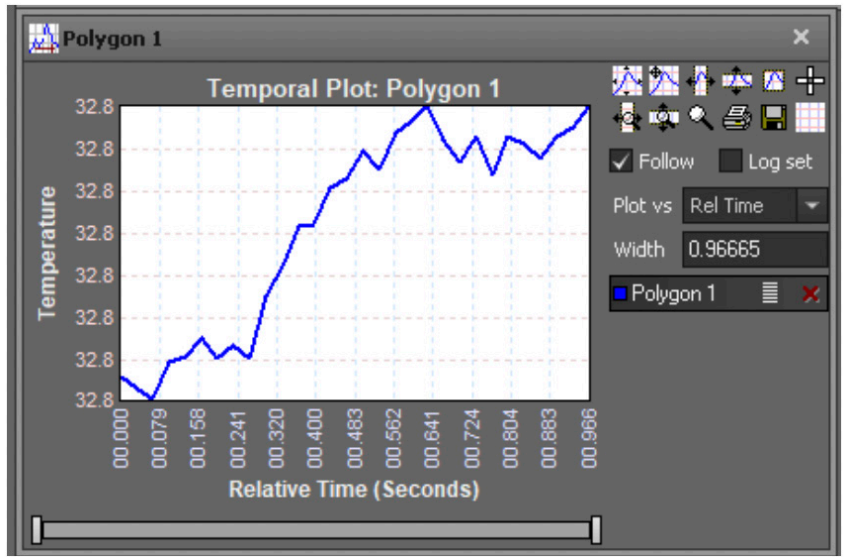

Figure 4. Temporary temperatures of the surface of the fabric placed on the hot plate.

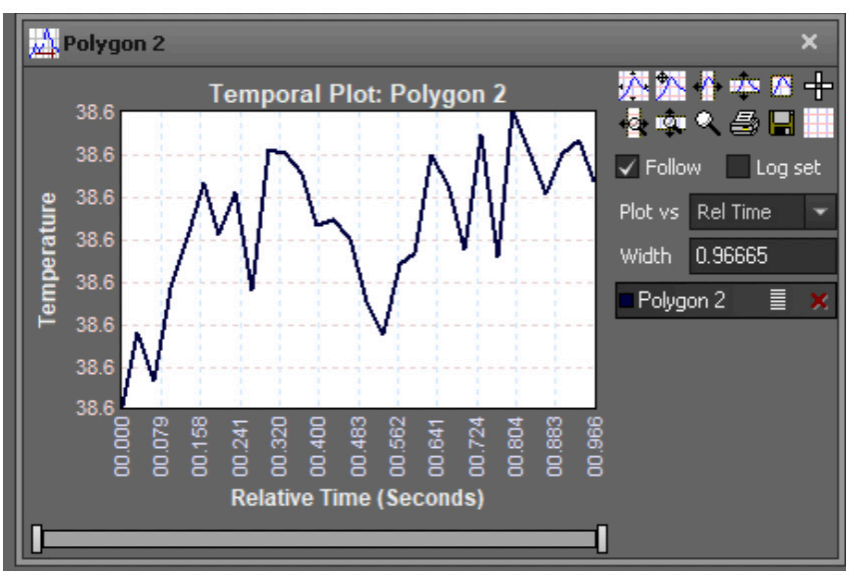

Figure 5. Temporary temperature of the hot plate surface.

temperature of the hot plate gives a bigger difference between the temperatures of the hot plate surface and the fabric surface.

Figure 6 also presents a comparison between the particular variants of fabrics being investigated. It can be assessed that the $1 / 2$ fabric variant (Figure 6 - green line) gives the biggest temperature difference between the plate surface and the fabric surface. It means that the 1/2 fabric variant ensures the best thermal insulation among all the investigated seersucker woven fabrics.

On the basis of the results from the thermographic method, an analysis was performed in order to assess the impact of the initial hot plate temperature on the temperature differences between the plate and the fabric surface. The results of the analysis for one type of fabric -the 1/1 variant - are presented in Figure 7 in the form of a surface graph (Figure 7a) and in the form of a color chart (Figure 7b).

The results are presented in the form of a box plot in Figure 8. The values represented in the form of a red line refer to the median value obtained for the time of 27 seconds of the test. Attempts to register the temperature of the fabrics and the heating plate in the initial stages of the experiment were carried out for various time intervals from 30 to 120 seconds (Figure 6). Based on these experiments, it was found that the determination of the thermal properties of individual fabrics can be carried out in the time interval of 30 seconds. For the assessment, tests

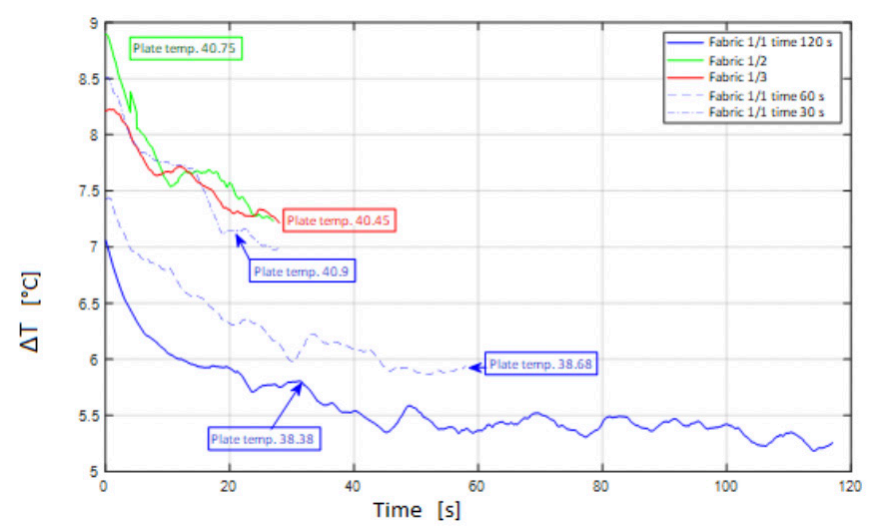

Figure 6. Difference between temperatures of the hot plate and the fabric surface vs. time.

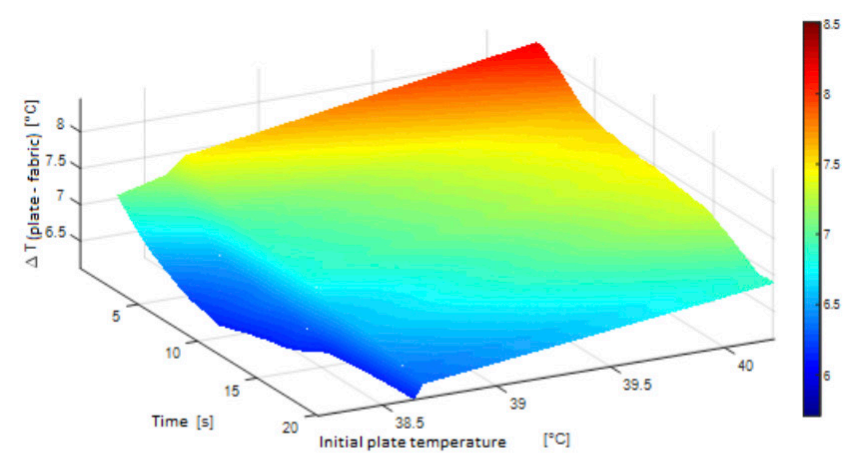

a)

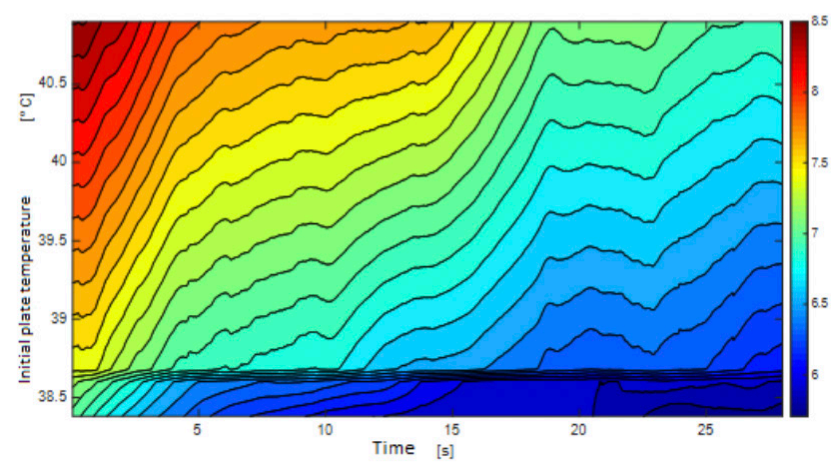

b)

Figure 7. The impact of initial hot plate temperature on the temperature differences between the plate and the fabric surfaces: (a) surface graph and (b) color chart.

were taken from 3 seconds to 30 seconds. This was due to the fact that in the first 3 seconds, the acquisition of thermal photos had started and it was necessary to take off the plate pressing the fabric to the hot plate. At that time, the hand and the pressure plate were visible in the eyeshot. Due to this fact, all tests were evaluated for 27 seconds, although data acquisition took place in the range of 30 seconds. The frequency at which the photos were taken is $30 \mathrm{~Hz}$. For this frequency, the amount of data taken into account for 27 seconds was 810 frames, each of which had a resolution of $640^{\prime} 480 \mathrm{dpi}$. Based on the graph of temperature differences for different types of fabrics, it can be stated that these differences stabilized at a certain level for a long time. The data in the form of a blue rectangle refers to half of the values recorded in the test. The width of the box corresponds to the value of the quarter range. The box drawing 


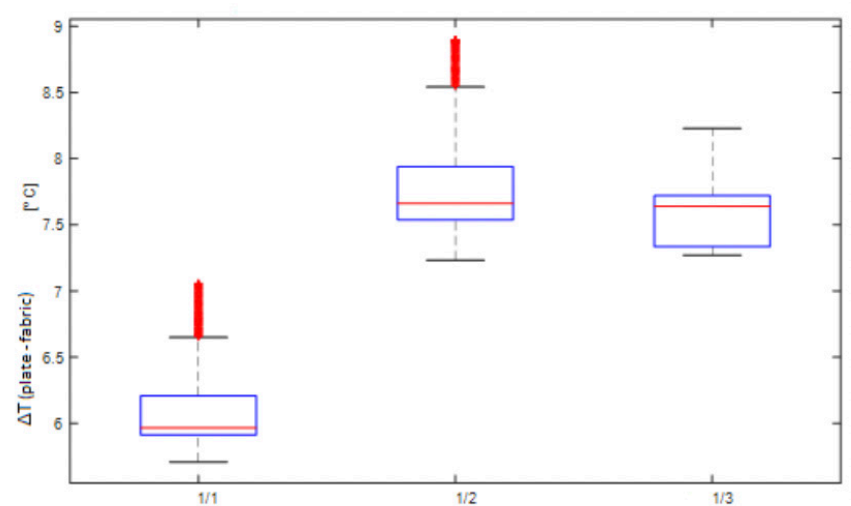

Figure 8. Comparison of the investigated fabric variants in the aspect of difference between the temperatures of the hot plate and the fabric surface.

is completed in the upper and lower sides with the maximum and minimum values of data observed. Data presented in the form of red crosses (observed for the $1 / 1$ and $1 / 2$ variants) represent values exceeding 2,698 standard deviation values. There are the so-called outliers.

Based on the results summarized in Figure 8, we can conclude that the greatest amount of heat penetrates the fabric marked with the symbol $1 / 1$, then for the $1 / 3$ variant, and the least for the $1 / 2$ fabric; the $1 / 2$ variant is thus the best thermal insulator. The difference between the mean values of the $1 / 2$ and $1 / 3$ variants is insignificant. However, we can see that a dispersion of results for the $1 / 2$ variant is much larger than for the $1 / 3$ variant. The stated dispersion of the result is absolutely justified by the structure of the investigated seersucker woven fabrics, especially their surface geometry. The surface of the investigated fabrics is heterogeneous, and this is a programmed and desirable feature of these fabrics.

It is difficult to explain the observed relationships between the patterns of heat transfer through the seersucker woven fabrics being investigated. In order to do it, it is necessary to quantify the surface geometry of the fabrics being investigated, which is a very difficult task. No research method has been proposed so far that would allow the characterization of the geometrical structure of seersucker woven fabrics. Heat transport through the seersucker woven fabrics is the result of the thickness and porosity of the fabrics, the share of the surface of the puckered strips in the total surface of the fabric, and the shape of the puckered strips, i.e., the depth of the concave places and the height of the convex places. This aspect will be the object of further investigations. The current work was aimed at the development and elaboration of a method that can be applied to measure the heat transport through seersucker woven fabrics and to check whether it is possible to assess the heat transfer separately through the puckered areas and the flat areas of the seersucker woven fabrics. The obtained results confirmed the propositions.

In the next stage of research, it was decided to examine the temperature differences in the puckered and smooth areas of the seersucker woven fabric. It was done for the $1 / 1$ fabric variant. In order to determine the temperature changes in the

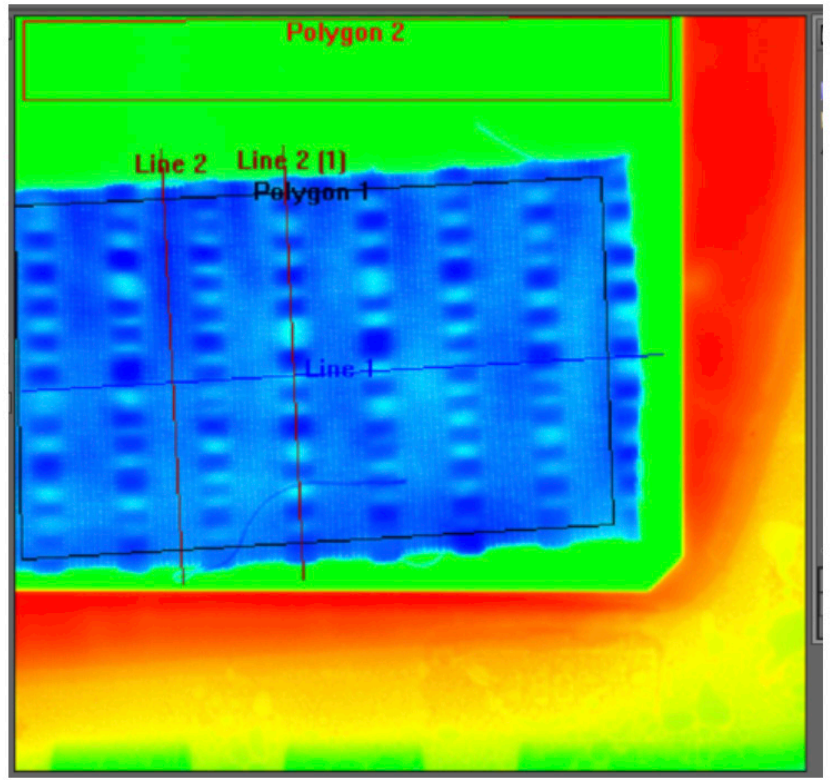

Figure 9. Placement of lines along the flat and puckered strips of the $1 / 1$ seersucker woven fabric.

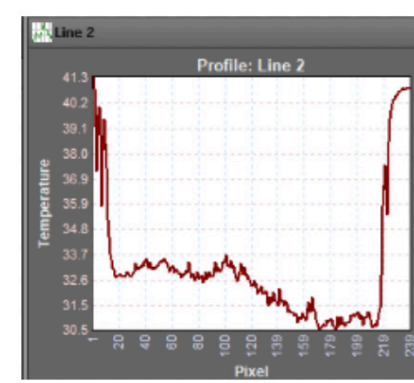

a)

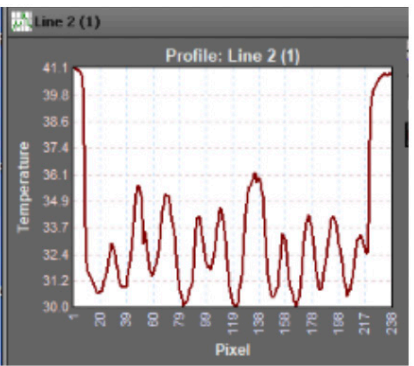

b)
Figure 10. Exemplary results of thermographic analysis for the $1 / 1$ fabric variant: (a) maximum temperature profile on the line in the flat area of the fabric (Line 2); and (b) maximum temperature profile on the line in the puckered area of the fabric (Line $2(1))$.

flat and the puckered areas of the fabric with respect to time, the following lines were used: Line 2 along the flat strip; and Line 2 (1) along the puckered strip (Figure 9). The position of these lines can be freely modified relative to the repeat of the seersucker effect. From these lines, in each frame of the thermal image sequence, the maximum temperatures were recorded over a time interval of 30 seconds. Exemplary charts for a time interval of 3-4 seconds are presented in Figure 10. In the measured area, Line 1 was created in the weft direction. Polygon 1 is placed on the sample area, whereas Polygon 2 is placed on the hot plate area not covered by the fabric.

From the thermographs, it can be seen that the profiles of the maximum temperature of the fabric surface along the flat and puckered strips have different shapes.

The lines 2 and 2(1) created along the flat and puckered strips are longer than the sample and reach beyond the edges of the sample (Figure 9). Due to this fact, we can observe the changes of surface temperature at the sample edges (Figure 10). The temperature at the beginning and the end of the lines 


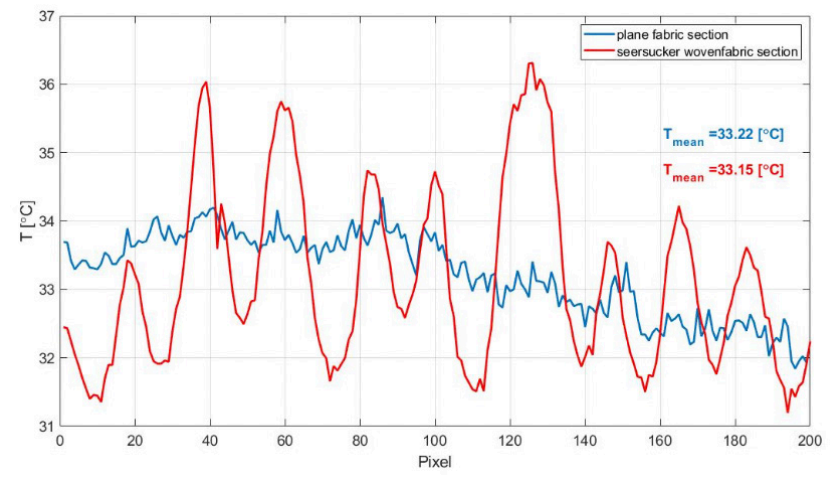

Figure 11. Temporary temperature of the fabric surface along the flat and puckered strips for the $1 / 1$ variant.

is $>40^{\circ} \mathrm{C}$. When the line begins to pass along the sample, the temperature drops drastically.

Figure 11 presents the temporary surface temperature for both lines, along the flat and the puckered strips. The results in Figure 11 indicate only the temperatures in the studied area of the sample surface.

It is clearly seen that the surface temperature varies significantly across the line along the puckered strip, whereas along the flat strip (blue line), the surface temperature is rather stable. The lowest temperature is in the convex places of the puckered strips. In these places, the distance between the fabrics and the surface of the hot plate is the largest. At the same time, the amount of air in the gaps between the hot plate and the fabrics is the largest, which causes high thermal insulation. The highest temperature along the puckered strips is in places where the fabric adheres to the hot plate. The temperature distribution along the flat strips is rather even, which results from the structure of the fabric in the flat area.

The average temperatures for both lines are quite surprising at the same level. It results from the fact that the flat area of the seersucker woven fabric is at some distance from the surface of the hot plate. The thermal resistance of air present in the gap between the surface of the hot plate and the surface of the flat area of the seersucker woven fabric is added to the thermal resistance of the fabric in the flat area.

Table 3 presents the data characterizing the temperature distribution across the lines. The differences between the lines (and, at the same time, between the flat and puckered strips of the fabric) concern mostly the maximum and minimum values of the temperature, as well as the variation of temperature along the lines. For the line created along the puckered strip, i.e., Line $2(1)$, the maximum temperature is higher than the maximum temperature for the line along the flat strip, viz., Line 2 . The same relation is found in the case of the standard deviation of the results. It is according to expectations because the variation of the surface topography of the fabric in the area of the puckered strip has to result in variations of the heat transfer from the hot plate to the environment through the sample.

Figure 12 presents the histograms of the surface temperature for Line 2 (blue columns) and Line 2(1) (red columns). For
Table 3. Results from the FLIR SC6000HS infrared camera for lines created along the flat and puckered strips

\begin{tabular}{|c|c|c|c|}
\hline Parameter & Unit & $\begin{array}{c}\text { Line 2 } \\
\text { (along flat strip) }\end{array}$ & $\begin{array}{c}\text { Line 2(1) } \\
\text { (along } \\
\text { puckered strip) }\end{array}$ \\
\hline $\begin{array}{c}\text { Mean } \\
\text { temperature }\end{array}$ & ${ }^{\circ} \mathrm{C}$ & 33.22 & 38.15 \\
\hline $\begin{array}{c}\text { Standard } \\
\text { deviation }\end{array}$ & ${ }^{\circ} \mathrm{C}$ & 0.60 & 1.31 \\
\hline $\begin{array}{c}\text { Maximum } \\
\text { temperature }\end{array}$ & ${ }^{\circ} \mathrm{C}$ & 34.35 & 36.31 \\
\hline $\begin{array}{c}\text { Minimum } \\
\text { temperature }\end{array}$ & ${ }^{\circ} \mathrm{C}$ & 31.84 & 31.20 \\
\hline
\end{tabular}

the line created along the flat strip, the most frequent class is $33.5^{\circ} \mathrm{C}-34.0^{\circ} \mathrm{C}$. In this class, there are 73 results $(36.5 \%$ of all results). For the line along the puckered strip, the most frequent class is $31.5^{\circ} \mathrm{C}-32.0^{\circ} \mathrm{C}$. In this class, there are 43 results, i.e., $21.5 \%$ of all results for the line.

Based on the values recorded for the $1 / 1$ fabric over a time period of 27 seconds, a comparison was made of the differences in temperature in the two areas, viz., flat and puckered, in relation

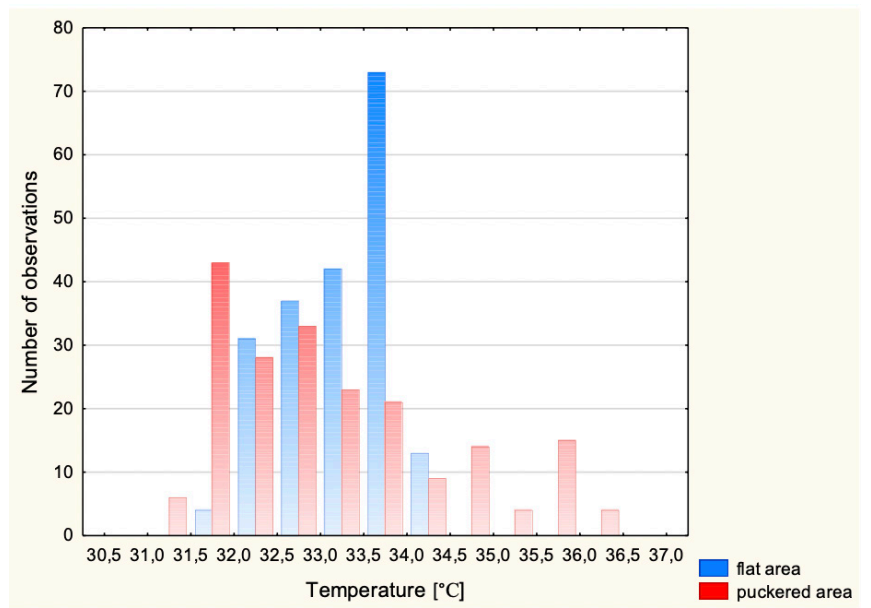

Figure 12. Histogram of the surface temperature values along the puckered and flat strips of the 1/1 variant of seersucker woven fabric.

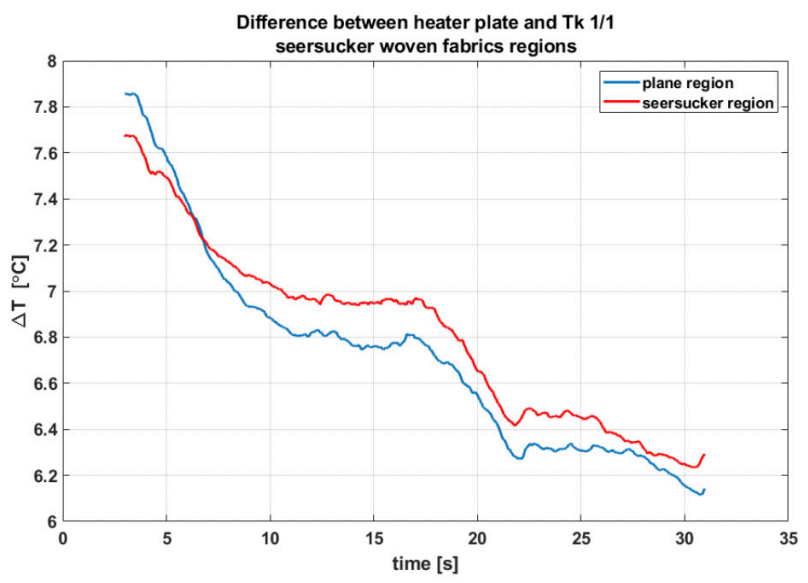

Figure 13. Comparison of the temperature difference between the hot plate surface and the two fabric areas, viz., puckered and flat, for the $1 / 1$ variant. 
to the temperature of the heating plate. The data acquisition period covered the time from 3 seconds to 30 seconds and was performed at a frequency of $30 \mathrm{~Hz}$. Comparison of the temperature difference between the hot plate and the two fabric areas is shown in Figure 13.

Based on the presented graphs, it can be concluded that after about 7 seconds, the temperature difference in the flat area changes its character and is lower in relation to the temperature of the puckered area. Thereafter, we observe a tendency toward equalization of temperatures in these areas, heat transfer being inhibited by the closed air in the puckered spaces. Analyzing both the thermal graph of the entire sample and the maximum temperature profile on Line 2 (1), it can be seen that the temperature of the convex areas is lower compared to the temperature of the fabric areas closer to the heat source. It should be noted here that the temperature of the hot plate $\left(38.2^{\circ} \mathrm{C}\right)$ is higher than the temperature of the analyzed fabric areas. Therefore, the smaller difference observed in Figure 13 corresponds to a higher temperature of the fabric because the temperature difference between the hot plate and the fabric is smaller.

The final stage of the analysis, intended for testing the thermal properties of the seersucker woven fabrics, was to check how the temperature profiles change in time along the flat and puckered areas. The collective results are presented in Figure 14. Subsequently, Figure 15 shows the temporary temperatures

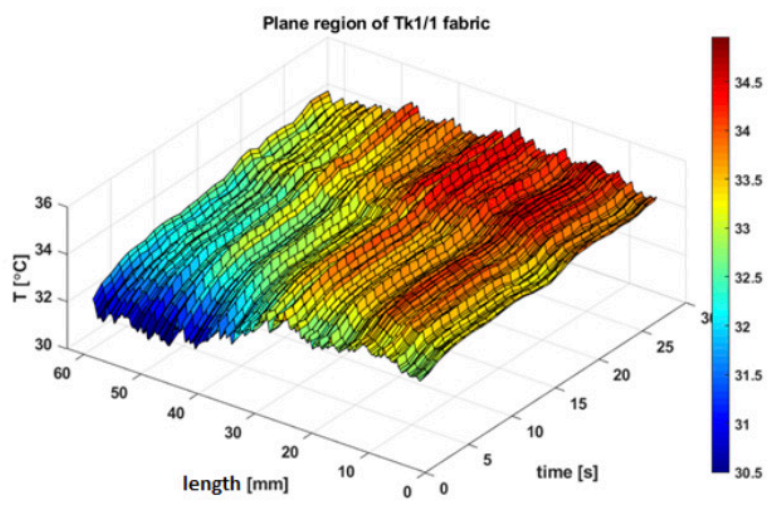

a)

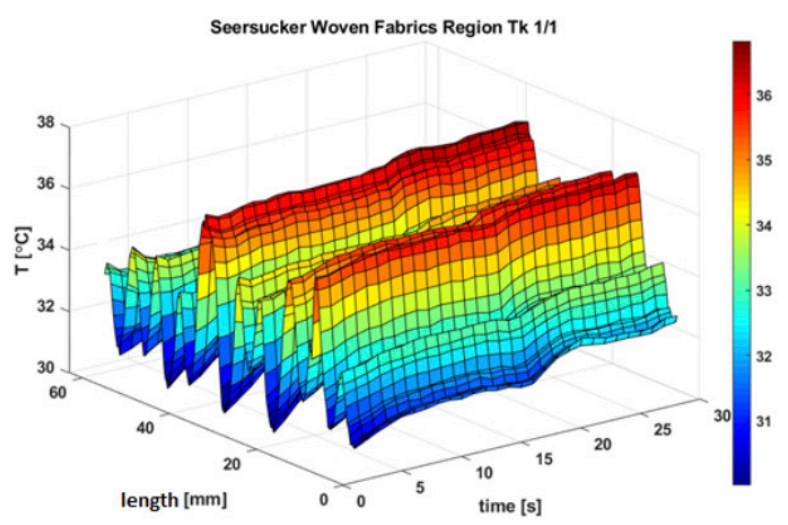

b)

Figure 14. Temperature profiles vs. time along the flat and puckered areas: (a) for the line created along the flat strip; and (b) for the line created along the puckered strip. as a function of the place in both the lines created along the flat and puckered strips.

As mentioned earlier, it is impossible to explain the relationships between the results from the infrared camera for the particular fabric variants being investigated. The heat transfer through fabrics, especially the seersucker woven fabric, is strongly connected with the structure of the fabrics. In the case of the seersucker woven fabrics, their structure is complicated due to the puckered effect occurring alternately with the flat fragments of the fabrics. This puckered structure, and especially the intensity of the seersucker effect, influences the heat transfer through the puckered area of the fabrics. Moreover, the intensity of the seersucker effect influences the distance between the hot plate and the flat fragments of the seersucker woven fabrics. Similarly, it influences the thermal resistance of the air between the hot plate and the flat area of the fabrics. In order to explain the stated relationships, it is necessary to analyze deeply the geometric structure of the seersucker woven fabrics being investigated. It can be done using a profilometer. Such investigations have been performed by Matusiak [12]. Preliminary investigations confirmed that the surface roughness of the puckered strips is different for fabrics made of different weft yarns. Investigations of the surface topography of seersucker woven fabrics are going on. Next, the heat transfer through seersucker woven fabrics will be studied in relation to the parameters characterizing the surface

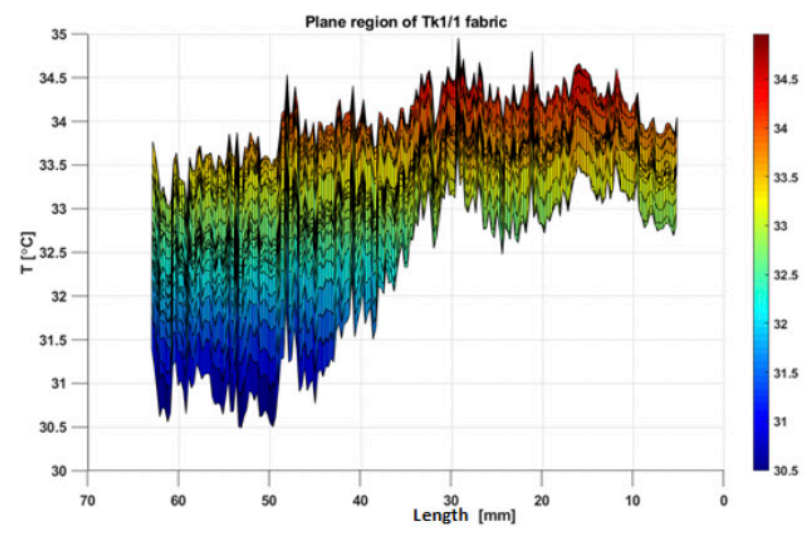

a)

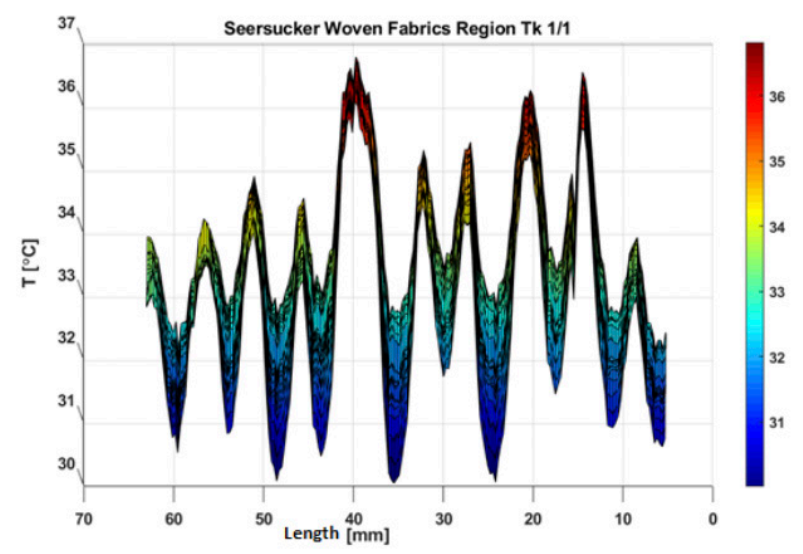

b)

Figure 15. Temporary surface temperatures along the strips: (a) flat; and (b) puckered. 
topography of the fabrics. The final results thus obtained will be the topic of future publications.

\section{Conclusion}

The presented investigations confirmed that the thermographic method can be applied to analyze the heat transfer through seersucker woven fabrics. In contrast to other methods used for the assessment of the thermal insulation properties of textile materials, the thermographic method allows the assessment of the heat transfer in particular places of the fabric. It is especially important in the case of the seersucker woven fabrics and other fabrics with varied surface topography.

Using an infrared camera, it was found that the distribution of the temporary surface temperature along the puckered strip varies significantly. The lowest temperature is in the convex places of the puckered strips. In these places, the distance between the fabrics and the surface of the hot plate is the largest. At the same time, the amount of air in the gaps between the hot plate and the fabrics is also the largest, which causes high thermal insulation. The highest temperature along the puckered strips is in places where the fabric adheres to the hot plate. The temperature distribution along the flat strips is rather even, which results from the structure of the fabric in the flat area.

It was found that the average temperature for the lines created along the flat and puckered strips is almost the same. It results from the fact that the flat area of the seersucker woven fabric is at some distance from the surface of the hot plate. The thermal resistance of the air in the gap between the surface of the hot plate and the flat area of the seersucker woven fabric is added to the thermal resistance of the fabric in the flat area.

Measurement using the thermographic method allowed us to compare the heat transfer through seersucker woven fabrics of different weft yarns. The results showed that the linear density of the weft yarn influences the heat transfer through the seersucker woven fabrics. The $1 / 2$ fabric variant gives the biggest temperature difference between the hot plate surface and fabric surface. It means that the $1 / 2$ fabric variant ensures the best thermal insulation among all the investigated seersucker woven fabrics.

\section{Acknowledgment}

This work was financed by the National Science Centre. Poland, within the framework of the project titled "Geometrical, mechanical, and biophysical parameterization of threedimensional woven structures", project no. 2016/23/B/ ST8/02041.

\section{References}

[1] Gandhi, K. (2012). Woven textiles principles, technologies and applications. (1st ed.). Woodhead Publishing (New Delhi).

[2] Ashraf, W., Nawab, Y., Maqsood, M., Khan, H., Awais, H., et al. (2015). Development of seersucker knitted fabric for better comfort properties and aesthetic appearance. Fibers and Polymers, 16(3), 699-701.

[3] Ghahraman, F. G., Tavanai, H., Hosseini, S. A. (2010). A qualitative assessment of seersucker effect through spectral density and angular power spectrum function algorithms. The Journal of the Textile Institute, 101(3), 276-281.

[4] Matusiak, M., Frącczak, t. (2010). Comfort-related properties of seersucker fabrics in dry and wet state. International Journal of Clothing Science and Technology, 29(3), 366-379.

[5] Bajzik, V., Hes, L., Dolezal, I. (2016, June). Changes in thermal comfort properties of sportswear and underwear due to their wetting. Indian Journal of Fibre \& Textile Research, 41, 161-166.

[6] Hes, L., Dolezal, I. (2003). A new computer-controlled skin model for fast determination of water vapour and thermal resistance of fabrics. 7th Asian Textile Conference, New Delhi.

[7] Akcagun, E., Bogusławska-Bączek, M., Hes, L. (2019). Thermal insulation and thermal contact properties of wool and wool/PES fabrics in wet state. Journal of Natural Fibers, 16(2), 199-208.

[8] Matusiak, M. (2006). Investigation of the thermal insulation properties of multilayer textiles. Fibres \& Textiles in Eastern Europe, 14(5), 98-102.

[9] Michalak, M., Więcek, B. (2008). Estimating thermal properties of flat products by a new non-contact method. Fibres \& Textiles in Eastern Europe, 16(4), 72-77.

[10] Michalak, M., Felczak, M., Więcek, B. (2009). Evaluation of the thermal parameters of textile materials using the thermographic method. Fibres \& Textiles in Eastern Europe, 17(3), 84-89.

[11] Matusiak, M., Sikorski, K. (2011). Relative thermal comfort index as a measure of the usefulness of fabrics for winter clothing manufacturing. Fibres \& Textiles in Eastern Europe, 19(6), 94-100.

[12] Matusiak, M. (2019). Investigation of surface topography of seersucker woven fabrics. Proceedings of 10th Central European Conference, Lodz. 